\title{
PRENSA, DEPORTE Y SOCIABILIDAD URBANA EN MÉXICO DF $(1851-1910)^{1}$
}

\section{NEWSPAPERS, SPORT AND URBAN SOCIABILITY IN MEXICO DF (1851-1910)}

\section{Chester Urbina Gaitán*}

\section{RESUMEN}

El estudio de la prensa capitalina mexicana durante el período de 1851 a 1909 en cuanto al nacimiento del deporte en México DF refiere que esta actividad nace en seno de la burguesía capitalina $y$ de las principales colonias extranjeras radicadas en esa urbe. En estos años el panorama deportivo estuvo dominado por disciplinas individuales, lo que incidió negativamente en la adecuada preparación y entrenamiento. Con el nacimiento del béisbol en 1897, los sectores trabajadores entran a la arena deportiva, por lo que se puede considerar que este deporte contribuyó en la formación de un sentido de clase entre esos grupos sociales.

PALABRAS CLAVE: MÉXICO * DEPORTES * PRENSA * EDUCACIÓN * CLASE ALTA

\section{ABSTRACT}

The study of the Mexican capital's newspapers during the 1851-1909 period as the birth of the sport in Mexico City refers to this activity comes within the bourgeoisie in capital and main foreign colonies located in that city. In these years the sports landscape was dominated by individual disciplines, which had a negative impact on the proper preparation and training. With the birth of baseball in 1897, the workers sector participated in sports, so we can consider that baseball contributed to the formation of recognition of class between these social groups.

KEYWORDS: MÉXICO * SPORTS * PRESS * EDUCATION * UPPER CLASS

$1 \quad$ El autor agradece los comentarios y observaciones a una versión preliminar de este texto al Dr. Gabriel Angelotti Pasteur, Dr. Miguel Lisbona Guillén y Dr. César Federico Macías Cervantes.

* Universidad Politécnica de Nicaragua (UPOLI).

chesterurbina@yahoo.com 


\section{INTRODUCCIÓN}

Con la llegada al poder de Benito Juárez (1858-1872) se comienza a estructurar un Estado nacional que se fundamentaba a un nivel ideológico sobre el liberalismo y el positivismo, que promovería el capitalismo y una identidad nacional asentada sobre el imaginario criollo (Hale, 1997: 824). Para Juárez era urgente buscar el desarrollo económico del país, el orden, la destreza y las actitudes favorables a la industrialización, que se obtendrían por medio de la educación. En esto jugó un papel fundamental Gabino Barreda, quien pensaba que para poner fin al caos en el que había vivido la nación se requería poner orden en la mente de los mexicanos y esto se conseguiría con la exaltación del pensamiento científico a través del positivismo (Vásquez, 2000: 56).

Por medio de la Ley Juárez (1855) y la Ley Lerdo (1856) se acentuaron más las reformas liberales, la primera pretendía afirmar la igualdad para todos los mexicanos ante la ley, al terminar con la inmunidad de oficiales militares y eclesiásticos, y al eliminar las cortes o leyes especiales para las clases privilegiadas. La segunda pretendía disolver los monopolios más grandes del país al forzar a la Iglesia a deshacerse de sus vastas propiedades. Estas dos leyes constituyen la base jurídica de la Constitución de 1857, la cual tenía como objetivo atacar la estructura de abusos y privilegios existente en el país (Roeder, 1952: 123). A finales del siglo xIx, México, a un nivel económico estaba formado por complejos regionales de tipo productivo, histórico y social, asociados a formas determinadas de reproducción, flujo y control de la fuerza de trabajo, $y$ también a movimientos $y$ sublevaciones. Para los indígenas, la vinculación agrícola con la economía mundial ocasionó la pérdida de sus tierras comunales y el ser enganchados en forma compulsiva a trabajar en condiciones de semiesclavitud, como sucedió en el Valle Nacional, la selva chiapaneca y Yucatán (Historia de la cuestión agraria mexicana, 1988 $y$ Gilbert, 1982).

La escasez de vías de comunicación, los accidentes geográficos $y$ la diversidad de culturas y lenguas dificultaban la tarea de educar a la población nacional. Pese a que en 1900, se comienza a fomentar una política para educar a la población indígena, esta siguió siendo elitista. En este año, el 84 \% de la población no sabía leer ni escribir (Instituto de Investigaciones Bibliográficas, 2008: 161).

En las últimas décadas del siglo xIx, el Estado mexicano estaba interesado en la promoción de una política de salubridad - anclada en el mundo citadino- alrededor de la profilaxis, es decir, la prevención de enfermedades. Con esto, el Estado se desentendía de su intervención en la curación de las mismas $y$ en elevar el nivel sanitario de las diferentes poblaciones. Si bien, en teoría, el pensamiento higienista es una propuesta de inclusión y de conservación de la vida, en la práctica, no llegó hasta los sectores populares, porque esos grupos sociales no tenían los parámetros de limpieza, pulcritud y civilización requeridos para la nueva nación (Toledo, 2009 y López, 2009).

Durante el régimen del General Porfirio Díaz (1876-1911) se realizaron obras públicas de gran envergadura como el Gran Canal de Desagüe del Valle de México y la reconstrucción y saneamiento del puerto de Veracruz. Además, el Consejo Superior de Salubridad fue una institución apoyada por Díaz para formular políticas de salubridad pública y proyectar a México como una nación americana que se dirigía hacia el progreso y la civilización. Entre los principales aportes de esta institución destacan la promoción de la medicina científica para la resolución de los problemas sanitarios, la aplicación de la vacuna antirrábica y el tratamiento para la tuberculosis basado en el análisis microbiológico y el saneamiento de la ciudad de México (Aréchiga, 2007).

"El Porfiriato" dio continuidad al proyecto de consolidación del Estado debido a que impuso un período de pacificación luego de que el país experimentara varias guerras durante todo el siglo xix. Este régimen apoyado en la ideología liberal ayudó a consolidar el Estado moderno en México al someter a la Iglesia y los poderes locales bajo su hegemonía. Fue un régimen marcadamente personalista que se apoyó en la habilidad de Díaz para establecer y mantener amistades y lealtades dentro del marco del patronazgo político. La forma de dominación 
se estructuró alrededor del debilitamiento del poder de los gobernadores y mantener el equilibrio entre los poderes y las elites regionales, así como, el uso del ejército para eliminar cualquier impugnación al poder estatal (Garner, 2003; Cosío, 1955-1972 y Guerra, 1988).

En la ciudad de México, para 1900, se contaba con alrededor de 400000 habitantes. La población capitalina se encontraba distribuida en forma muy irregular, concentrada en los estados del centro y en la ciudad de México. El 14\% de la población sabía leer en 1895 y un $20 \%$ en 1910. El Distrito Federal tenía el índice de alfabetismo más alto del país; en 1895 se calculó en un 38\% y llegó al 50\% en 1910 (PérezRayón, 1998). En este año, la ciudad se extendía sobre una superficie de $40 \mathrm{~km}^{2}$, con una población de 471 mil habitantes (Garza, 1992: 238).

Sobre la importancia historiográfica del estudio del deporte debe indicarse que esta radica en el hecho de que, permite un acercamiento a los ámbitos de la sociabilidad, de las conductas de los colectivos humanos y de la simbología. El mundo deportivo es un mundo con redes complejas, poco exploradas, por lo que es necesario comprender la manera como las asociaciones deportivas se van formando $y$ desarrollando. En este proceso participan lo social-conductual junto a lo simbólico, donde el deporte contribuye a la formación de una identidad de un determinado grupo humano, que lo convierte en un área de investigación poco explorada por la historia cultural (Urbina, 2006a y 2006b).

El nacimiento del deporte moderno ocurre con la industrialización de la sociedad inglesa $y$ de otros países del continente europeo, lo cual estuvo ligado a mejoras de las condiciones de vida de los trabajadores, desarrollo urbano, multiplicación de los medios de transporte y comunicación, crecimiento demográfico, evolución y consolidación de los sistemas democráti$\cos y$ aparición de nuevos valores sociales como eficiencia, productividad y competitividad. Tales condiciones son las que permitieron la evolución del deporte moderno en todos sus aspectos y su posterior expansión a escala planetaria (Pérez, 2002).
La importancia social del deporte consiste en su carácter oposicional, puesto que el enfrentamiento sirve para cimentar la identificación como grupo; es decir, el sentimiento de "nosotros" como grupo, como unidad, se refuerza ante la presencia de otro grupo percibido como "ellos", sea local o nacional, y sus seguidores. Para Dunning, esto ocurre en efecto dentro de los Estados-naciones internamente pacificados; o sea, en las sociedades en que el Estado ha monopolizado el derecho a emplear la fuerza física, el deporte proporciona a las unidades sociales grandes, complejas e impersonales - como las ciudades - la única oportunidad de unirse (citado en Elías y Dunning, 1996). También debe comprenderse que la construcción social del tiempo libre no depende únicamente de un solo factor preponderante (económico o educativo), sino del entrejuego de múltiples variables que se modulan recíprocamente. Además de la posición social, son notoriamente importantes el género y la edad (García, 1995).

Con respecto a los estudios sobre los inicios de la práctica del deporte moderno en la ciudad de México, se han realizado varias publicaciones, una de estas es el libro de Juan Pedro Viqueira Albán: ¿Relajados o reprimidos? Diversiones públicas y vida social en la ciudad de México durante el Siglo de las Luces, donde refiere que en la ciudad de México existió una cancha que poseía la orden de San Camilo a mediados del siglo xvir. En este lugar se comienza a impedir el ingreso de la plebe, debido a que los comerciantes quisieron prohibir la entrada y para esto hicieron que se cobrara una cuota de medio real por la entrada a las gradas (Viqueira, 1987). El motivo de esta prohibición no era tanto el hecho de que la plebe organizara desórdenes, sino más bien, el cobrarle la entrada a este juego con la excusa de decir que se estaban dando conflictos en este lugar.

Otra publicación es la de Gerson Zamora, titulada El deporte en la ciudad de México (1896-1911) que comienza su estudio a partir de 1896, con el nacimiento del periódico deportivo Mexican Sportsman y la fundación del Reforma Athletic Club (Zamora, 2011). A través del estudio de obras secundarias - principalmente- hace una descripción de las principales 
disciplinas deportivas que se ejecutaban en la capital; sin embargo, no enmarca a nivel cultural la competencia entre el deporte moderno y las diversiones públicas, el papel del Estado en la promoción de la higiene, la expansión urbanística del Distrito Federal, el acceso sectorial a la modernidad y el papel del beisbol en la formación de un sentido de clase entre los sectores trabajadores. No brinda una precisión histórica con respecto a la evolución del deporte, pues no se habla de disciplinas como el boxeo, la lucha grecorromana, el automovilismo y el jiu jitsu, por ejemplo. Otro trabajo descriptivo es el de Martín Mendoza Ruíz, El deporte en México en la época contemporánea (19/01/2012).

Por otra parte, Gabriel Angelotti Pasteur en Deporte y nacionalismo en México durante la post revolución, hace un análisis más crítico sobre el impacto diferenciado de la modernidad $y$ del acceso al deporte durante "El Porfiriato". Acota que los indígenas capitalinos no tuvieron acceso a la práctica del deporte, además, señala que el único intento realizado durante el gobierno de Porfirio Díaz para expandir la práctica deportiva y gimnástica fue su inclusión en los programas de estudio de las escuelas en el año de 1889. Esta decisión estaba sustentada en aquella idea que considera a los deportes como un medio adecuado para desarrollar la percepción, la resolución, la velocidad física y así evitar la pereza de los alumnos (Angelotti, 2011).

Fundamentado en todo lo anterior es que el presente artículo tiene como objetivo realizar un estudio histórico-social sobre el nacimiento del deporte en México DF durante el período de 1851 a 1909 y el papel que la prensa le concedió al deporte en la modernización de la sociabilidad capitalina. Los años de estudio se han dividido en dos sub períodos: el primero comprende desde el establecimiento del primer hipódromo en la capital en 1851 hasta 1882 y el segundo corte temporal abarca desde la fundación del Jockey Club de México en 1883 hasta 1910, con el inicio de la Revolución Mexicana.

\section{PRENSA, DIVERSIONES PÚBLICAS Y DEPORTE} EN MÉXICO DF (1851-1882)

En 1852, La Semana de las Señoritas Mejicanas daba a conocer: "Educación física de las jóvenes" del Dr. La Llemand, en este tratado se señalaba que el medio más eficaz de combatir los desordenes producidos por una sensibilidad demasiado exaltada, es el desarrollo progresivo del sistema muscular con el auxilio de ejercicios variados más enérgicos y prolongados. Este es el verdadero remedio contra los males de nervios, contra los vapores y contra todos los afectos espasmódicos que son la consecuencia de la inacción en que viven las personas acomodadas. Además, se señalan los beneficios de la práctica de la natación y la esgrima (La Semana de las Señoritas Mejicanas, 1852: 200-201). En esta época la limpieza era lo que distinguía a la llamada "gente de bien" de la clase baja. Se relacionaba el nivel moral de la persona con su higiene, $y$ que no había promoción social sin que se efectuara un cambio de hábitos y costumbres (Glantz, 1997: 212).

Con respecto al trastocamiento del espacio destinado al ocio se tiene que en el carácter lúdico del ser humano sobresale el componente social del juego y su historicidad (González, 1993). La actividad lúdica —ya sea en su forma controlada como en la no reglamentada- expresa el conflicto social, el simbolismo y la creación de identidades. En los discursos hegemónicos sobre la vagancia a finales del siglo xvII y principios del xix, señalan que detrás de los diversos argumentos desarrollados en contra de determinados comportamientos prohibidos, estaba el afán de controlar a las clases subalternas. Se trataba de una política de control social que se ampliaba a medida que la población desempleada aumentaba y con ella los problemas de tranquilidad pública (Lida y Pérez, 2001: 19-65).

Para el jueves 3 de diciembre de 1868, el periódico La Iberia señalaba que tanto el ayuntamiento como la junta de mejoras de Tacubaya se habían manifestado en contra de las peleas de gallos en esa población, considerándolas como: "inmorales y ruinosas" (1868: 3$)$. En 1870, Crescencio Ortega del Villar se manifestaba en contra de estas lides $y$ de las corridas de toros pues fomentaban la inhumanidad $y$ el maltrato a los animales, aparte de que las clases pobres $y$ trabajadoras despilfarraban su salario en apuestas (El Ferrocarril, 1870: 1-2). 
Sobre las carreras de caballos en la capital mexicana se tiene que para el domingo 18 de mayo de 1851, se realizaría en el hipódromo capitalino una carrera de mil quinientas varas entre el caballo "Diamante" y una yegua que acababa de llegar de Estados Unidos (El Monitor Republicano, 1851: 4). Para el domingo 19 de enero de 1868, en el hipódromo mexicano se efectuarían varios actos de entretenimiento, entre ellos: actos de equitación y la lucha entre el extranjero Pohl y el mexicano Olvera ( $E l \mathrm{Mo}$ nitor Republicano, 1868: 4). Para el domingo 23 de abril de 1882, se anunciaba la inauguración del hipódromo de Peralvillo con un gran premio de 1500 pesos (El Monitor Republicano, 1882: 4). En 1883, se inauguró el Jockey Club de México (El Diario del Hogar, 1883: 1), el cual era uno de los principales centros de sociabilidad de la elite capitalina (Beezley, 2004). Con respecto a la esgrima esta fue una disciplina deportiva que estuvo ligada al ejército. Así, en 1851, entre la planta de profesores del Colegio Militar estaba la de un catedrático de esgrima con un sueldo de 600 pesos (Legislación Mexicana, 1877: 57).

En cuanto a la gimnasia, se tiene que el Archivo Mexicano, que en 1853 don Joaquín Castro era el comandante de la escuela general de gimnasia (1853: 580). El 7 de noviembre de 1869, se emite el Reglamento del Colegio Militar, en el cual se establece que en el área de instrucción accesoria, los alumnos admitidos en dicho centro debían de llevar clases de gimnasia y natación (Legislación Mexicana, 1878: 750). Asimismo, en 1870, en este Reglamento, los alumnos debían de llevar clases de gimnasia, natación y esgrima (El Derecho, 1870: 452). Posteriormente, el Reglamento de las Escuelas Nacionales primarias para niños (12 de enero de 1879) establece clases de gimnasia en todos sus niveles (Legislación Mexicana, 1886: 728-730). En 1880, en el Reglamento de la Escuela Nacional de Sordomudos en sus primeros ocho años de clases, se establece la práctica de la gimnasia (Legislación Mexicana, 1886: 194-196). En este mismo año, se establece en el Reglamento para las Escuelas Nacionales primarias y secundarias de niñas, las clases de gimnasia (Legislación Mexicana,
1886: 645). Con respecto a la utilidad de la gimnasia debe aclararse que uno de sus principales objetivos fue la formación de cuerpos saludables, resistentes a las enfermedades y fuertes para el trabajo que el mundo capitalista exigía, como el de las fábricas. El cuerpo tenía que evidenciar los avances científicos y médicos para constituirse en datos de la modernidad anhelada por los grupos políticos $y$ científicos de la época. La regeneración racial y la armonía del cuerpo también fueron partes esenciales del discurso higiénico. Con el movimiento de ciertas partes del cuerpo se pretendía corregir las "posturas defectuosas", para lograr así la perfección estética y el "mejoramiento de las razas" (Chávez, 2004).

Acerca de la natación, en 1864 se abrió la Alberca Pane, cuyo dueño era don Sebastián Pane (El Ferrocarril, 1871: 4). A inicios de diciembre de 1871, el Ateneo Mexicano Escuela Universal Preparatoria para todas las carreras indicaba que con arreglo a las posibilidades económicas de cada alumno, se cursarían las clases de gimnasia, natación, esgrima, tiro de pistola, pugilato, equitación, entre otras (The Two Republics, 1871: 3). En mayo de 1872, una compañía circense efectuó varias competencias de natación: una entre un maestro de natación $y$ el chino Fidel Amen Chan, otra entre dos señoras y una niña, así como una de ida y vuelta boca abajo (El Monitor Republicano, 1872: 1). A principios de junio del año antes citado, don Sebastián Pane daba clases de natación en la Rinconada de San Diego (El Monitor Republicano, 1872: 3).

El 10 de abril de 1874, se inauguró la Sociedad Médico Homeopática Mexicana. Después de efectuada esta actividad en los salones de esta entidad médica, los socios e invitados se reunieron entre una y dos de la tarde, en el Tívoli del Ferrocarril, llamado de Veracruz, donde jugaron al boliche (El Faro Homeopático, 1874: 7).

Fundamentado en todo lo anterior, se ha podido constatar que el deporte nace dentro del seno de la burguesía de la ciudad de México, ya que esta disponía del ocio y el dinero suficiente para mantener caballos de raza, un club deportivo y comprar uniformes $y$ aparatos deportivos, amén de tener la preocupación por su 
salud y apariencia física. Los diversos usos de los bienes culturales - entre ellos el deporte- no solo se explican por la manera como se distribuye la oferta $y$ las alternativas culturales, o por la posibilidad económica para adquirirlos, sino también y principalmente, por la posesión de un capital cultural $y$ educativo que permite a los sujetos consumir, asistir y disfrutar las alternativas factibles. Las condiciones de vida diferentes producen hábitus distintos, ya que las condiciones de existencia de cada clase imponen maneras de clasificar, apreciar, desear y sentir lo necesario (Bourdieu, 1988 y Angelotti, 2004).

\section{PRENSA, SOCIABILIDAD URBANA Y DEPORTE EN MÉXICO DF (1883-1910)}

En 1889, El Municipio Libre reproducía un artículo de El Siglo Diez y Nueve donde señalaba que la Comisión de Instrucción Pública del cabildo de la capital, estudiaba el proyecto presentado por don Francisco P. Vera, relativo al establecimiento de un gimnasio para uso de las escuelas municipales, conteniendo juego de pelota y baños de regadera y de inmersión ( $E l M u$ nicipio Libre, 1889: 1). Lo anterior confirma lo señalado por Nora Pérez-Rayón en cuanto a que para fines del siglo xix, en la ciudad de México, los sectores de clase media urbanos, mediante la ciencia se sentían como ciudadanos del mundo, como gente decente y civilizada. Existía un sentimiento nacional de orgullo, se aplaudían los logros en el acceso a la modernidad y sus valores: la eficiencia, la productividad, la salubridad, la higiene, el conocimiento actualizado, la técnica, entre otros (Pérez-Rayón, 1998).

Sin embargo, no todos los sectores sociales aceptaron esta modernización cultural, para inicios de agosto de 1892, un cronista de El Siglo Diez y Nueve que tenía por pseudónimo "xyz" acotaba que:

En nuestra educación, bastante imperfecta, no se nos exigió desarrollar nuestros miembros en los sanos aparatos de la gimnasia, bajo la vigilancia de un profesor inteligente; $y$ crecimos raquíticos, con carnes lacias y músculos enjutos; no hemos robustecido nuestro cuerpo en las paralelas; preferimos mal nutrirnos intelectualmente, olvidando la sentencia latina del mens sana; $y$ ahora, de un modo imprevisto, por ese fenómeno de imitación tan común en las razas débiles, nos entregamos a los juegos de sport, con un risible delirio. No estamos preparados; no somos agiles, ni fuertes, ni sanos; pero no importa -así y todo hemos recibido con entusiasmo las nuevas diversiones (El Siglo Diez y Nueve, 1892: 2 y Torres, 1996).

De la cita anterior es notoria la visión conservadora apegada al tradicionalismo frente al avance de la práctica del deporte.

Con respecto al fútbol, el cronista Héctor de La Patria de México señalaba en 1897 que este deporte era el más bárbaro, más brutal y más inhumano que se había conocido. Sobre la regeneración de los mexicanos a través de la práctica del fútbol enfatizaba:

El foot-ball, dicen, es un juego vigorizador para esta raza anémica y enfermiza, para esta raza liliputiense y exangüe... que viva el juego de las zancadillas, de la brutalidad y la bofetada limpia; ino le hace que se rompan dos o tres cabezas $y$ las piernas y un brazo; esto es pequeño sacrificio ante la regeneración de una raza enfermiza! (La Patria de México, 1897: 1).

En 1908, se recomendaba que el deportista no debía ingerir licor debido a que el alcohol aumentaba $y$ aceleraba la fatiga por el agolpamiento de la sangre con sustancias impuras y venenosas (El Abogado Cristiano, 1908). Para 1910, un periódico capitalino comunicaba que el gobierno del General Díaz adoptó en todas las escuelas la práctica de la gimnasia sueca, que aunque no era tan ventajosa como la cultura física, pero era de bastante utilidad. La cultura física es un ejercicio proporcionado al individuo que lo practica $y$ tiene por objeto facilitar todas las funciones fisiológicas, al mismo tiempo que desarrollar todos sus músculos, pues no solo sirve para formar atletas, sino para crear hombres sanos y robustos (El Imparcial, 1910). Esto comprueba lo señalado por Beatriz 
Alcubierre (2004) y Claudia Agostoni (Clark de Lara y Speckman, 2005: 171-182) sobre el interés del Estado mexicano desde el siglo xix de instruir, moralizar y transmitir un sentimiento de identidad nacional a la población infantil urbana acomodada principalmente.

El domingo 18 de setiembre de 1910, El Imparcial publicaba un artículo denominado: "Las mujeres y el sport" donde resaltaba que las mujeres que se acostumbran al ejercicio corporal metodizado, son sanas, vigorosas y bellas. Asimismo, si las madres quisieran apropiarse de esta idea, harían que sus hijas desde pequeñas tonificaran su organismo por medio del deporte. Los deportes recomendados a las mujeres eran la equitación, el patinaje, el beisbol, el golf $y$ el tenis. No se les recomienda ni el ciclismo ni la caza. Acerca del ciclismo señala: "una mujer en bicicleta se ve fea $y$ en ocasiones ridícula $y$ la belleza femenina, su gracia y su atractivo no deben sacrificarse inútilmente" (El Imparcial: sp). Acerca del acceso al deporte por parte de las niñas mexicanas a principios del siglo $\mathrm{xx}$, aunque en los manuales escolares de lectura se les identificaba como un ser corpóreo, era considerado sobre todo como un sujeto espiritual. Desde pequeñas se les instruía sobre la mayor importancia que tenía el alma sobre el cuerpo (Boletín del Instituto de Investigaciones Bibliográficas, 2005).

Según se ha podido comprobar en los inicios de la práctica del deporte en la ciudad de México, no era raro que algunas mujeres, esposas de banqueros, comerciantes e inversionistas extranjeros practicaran los juegos oriundos de sus países natales, junto con algunos elementos jóvenes de la burguesía capitalina. A la par de esta selecta actividad, considerada como algo propio del ámbito exclusivo de los sectores más acomodados, es notorio que la mujer perteneciente a los sectores subalternos de la sociedad, tenía vedada la práctica de estas actividades, ya que se consideraba que eran impropias de su género, imagen que calzaba perfectamente con la mentalidad patriarcal que imperaba (Urbina, 2010).

Existen pocos trabajos que aborden la naturaleza patriarcal del dominio masculino en el deporte moderno y el papel que este pueda representar en el mantenimiento de la hegemonía masculina sobre la sociedad. Sin embargo, hay que apuntar que respecto a la producción y reproducción de la identidad masculina, el deporte solo tiene una importancia secundaria de refuerzo, ya que en tanto el proceso de socialización de las mujeres las haga sentirse atraídas por los hombres machistas, los deportes $y$ principalmente los de combate como el fútbol, continuarán contribuyendo de una forma relativamente importante a la perpetuación, tanto del machismo como de la dependencia de las mujeres derivada de este (Elías y Dunning, 1996).

El acceso de la mujer a la práctica del deporte, radica en el nacimiento de los Estados modernos y la instalación de sus aparatos ideológicos, lo cual permitió el surgimiento de un proceso de dominación hegemónica donde la salud es utilizada no solo desde una perspectiva de la medicalidad, sino como herramienta para moralizar e inculcar hábitos y costumbres morales y sanitarias entre los sectores subalternos (Ariès y Duby, 1999). Los avances médicos en el conocimiento del cuerpo de los niños y de las mujeres fueron utilizados en Francia por los sectores gobernantes para mantener su sistema de control social, lo cual originó una cultura de conservación de la apariencia física desde finales del siglo xix (Ariès y Duby, 1999).

En 1890, funcionaba el club de regatas Lakeside Boating Club (The Two Republics, 1890). Esta asociación deportiva organizaba competencias en los lagos de Chalco y de Xochimilco. Para 1893, se tiene conocimiento que el jueves de corpus de ese año murió de un golpe un pelotari de apellido Aldazabal. Con respecto a la pelota vasca se sabe que para el jueves 4 de junio de 1896, se realizaron varios partidos, sobresaliendo entre ellos el que se efectuó entre Urrutia, Aritzi y Hernani (azules) contra Iribarren, Artia y Aldazabal (colorados) a 30 tantos. Antes de llegar a la primera decena, el partido fue suspendido debido al pelotazo recibido en la cabeza al jugador Aldazabal ( $L a$ Voz de México, 1896). Para 1895, se inauguró el primer Frontón de la ciudad de México (The Mexican Herald, 1895).

Respecto al ajedrez, se conoce que en agosto de 1894, se efectuaron en La Habana 
varias partidas entre el cubano Andrés Clemente Vásquez y el ajedrecista amateur mexicano Márquez Sterling. El resultado final de las partidas fue el siguiente: el señor Vásquez gano 4, el señor Sterling no ganó ninguna y una partida quedó tablas (El Mosaico, 1894). En 1909, el fabricante de postizos franceses don Rodolfo Pokorny obtuvo el primer premio en el torneo internacional de ajedrecistas de México. Este era el primer torneo del Club Internacional de Ajedrecistas de México, el cual fue fundado por el Lic. E. Requena y el señor Tower, Ministro de Inglaterra, entre otros (El Mundo Ilustrado, 1909).

Acerca del ciclismo, a mediados de julio de 1895, en el Distrito Federal en uno de los parques de la Alameda, se había establecido una asociación de ciclistas, bajo la forma de Sociedad Anónima, de la que era tesorero el conocido comerciante C. Van der Wingaert (Diario del Hogar, 1895). Los ciclistas iniciarían sus prácticas el 29 de agosto a partir de 3 de la tarde a 11 de la noche. La Sociedad "El Ciclismo" solo haría su fiesta de inauguración cuando todos los velocípedos hayan llegado de los Estados Unidos (El Partido Liberal, 1895). El 22 de diciembre de 1895, se construyó el velódromo de la Piedad por el Cyclist Union Club. La inauguración fue apadrinada por los señores Manuel González Cosío, Ministro de Gobernación; Pedro Rincón Gallardo, Gobernador del Distrito y Sebastián Camacho, Presidente del Ayuntamiento; con sus respectivas familias ( $E l$ Monitor Republicano, 1895).

A mediados de enero de 1896, el Ayuntamiento capitalino le comunicaba a don Adolfo Isaac Riveroll, gerente de "El Ciclismo" que disponía de un mes para quitar el tren de bicicletas que tenía esa sociedad en la Alameda, ya que deslucía el aspecto del único parque que tenía la ciudad (El Demócrata, 1896). Esta misma entidad pública acordó que para el 18 de febrero de 1896, martes de carnaval, se realizaría un concurso de bicicletas adornadas (Diario del Hogar, 1896). A inicios de octubre de 1896 , se comunicaba que varios oficiales de gendarmería continuaban recibiendo clases de ciclismo en la escuela del Paseo de la Reforma, debido a que se iba a introducir ese nuevo servicio de policía (El Siglo Diez y Nueve, 1896). Los policías en bicicletas comenzarían a funcionar a partir del 1 de noviembre del año antes citado (El Siglo Diez y Nueve, 1896). Para el 14 de julio de 1899, la colonia francesa conmemoró con varias carreras ciclistas el aniversario de la toma de La Bastilla en el velódromo de la Piedad. A este acto asistieron el Ministro Francés Jorge Benoit y el presidente Porfirio Díaz ( $E l$ Universal, 1899 y Rodríguez, 1998). Para el domingo 9 de setiembre de 1900, en el velódromo de la Piedad se realizarían carreras de burros y juegos de cintas (El Universal, 1900). En agosto de 1900, se fundó el club ciclista Mercurio, el cual estaba integrado por jóvenes mexicano dedicados al comercio, quienes pretendían estrechar sus vínculos de compañerismo. La idea partió de los señores Francisco Bellido, Enrique F. Miranda, Rafael Domínguez y Alfredo Moulat (El Mundo Ilustrado, 1900). Para 1910, el club ciclista México estaba organizando una serie de carreras que se efectuarían en el velódromo de su propiedad (El Imparcial, 1910).

Con respecto al boxeo, a finales de noviembre de 1895, se encontraban en el Distrito Federal los pugilistas Clark y Smith. Saldrían en tren para Pachuca con el fin de aclimatarse al lugar para una pelea que se efectuaría el 24 del mes en mención (El Demócrata, 1895). En 1903, se informaba de la existencia del pugilista Enrique Ugartechea (El Tiempo, 1903). Para octubre de 1907, se encontraba en la capital, Kid Mitchel, quien saldría a Guanajuato para arreglar con Andrew Ennis, los términos en que se realizaría la pelea contra el australiano Jim Smith (La Iberia, 1907). A mediados de febrero de 1909, los pugilistas mexicanos ejecutaban peleas en el puerto de Veracruz, pero la autoridad municipal de ese lugar, cansada de los escándalos ocasionados por esta actividad, prohibió que se hicieran allí. Los boxeadores emigraron al Oro, Estado de México, donde los combates eran celebrados en esa población minera por los estadounidenses que allí vivían. Se sabe que pronto se realizaría una pelea entre Kid Lavigue y Cuauhtémoc Aguilar (La Iberia, 1909).

El miércoles 25 de agosto de 1909, en el Frontón Nacional, se verificaron un partido de pelota vasca y una pelea de boxeo, dedicadas a las víctimas de las lluvias en Acapulco (El Imparcial, 
1909). En este último año, se tenía la siguiente opinión sobre el pugilismo: "Esas luchas no sólo son inmorales por lo bárbaro del espectáculo..." (La Iberia, 1909: sp). Para esta época, el referee no podía parar una pelea -aunque un púgil estuviera recibiendo una paliza - hasta que uno de los boxeadores cayera. Esto lo permitían las reglas del marqués de Queensberry, por lo que el pugilismo era considerado como una diversión brutal (Urbina, 2011).

Acerca del atletismo se conoce que en 1896, en el velódromo de la Piedad, un señor de apellido Butlin hizo un salto con garrocha de 8 pies y 3 pulgadas; asimismo, ganó la carrera a pie que se efectuó en este lugar (El Nacional, 1896). A finales de junio de 1902, el Reforma Athletic Club efectuó una serie de competencias atléticas en honor del rey ingles Eduardo viI. La primera carrera, en terreno plano, fue ganada por M.S. Turner; la segunda, para muchachos de menos de 15 años por Luis Mosser; la tercera, que fue de obstáculos, por E. Emonds; la cuarta por Oscar Braniff y la quinta por Horacio Sharp. En las carreras para mujeres ganó la señorita Theele (El Mundo Ilustrado, 1902).

En 1908, el Junior Club efectuó en los patios de la Escuela de Mascarones, varias carreras, la primera se realizó en un tiempo de 2 minutos y 17 segundos ganándola un señor de apellido Miranda. La segunda, de 75 yardas, se realizó entre tres grupos de jugadores, ganándola don Jorge Parada. Luego se efectuaron carreras de burros y de sacos (El Mundo Ilustrado, 1908).

Para 1897, en el curso preparatorio para los Oficiales de Guerra se encontraba la materia de gimnasia (Legislación Mexicana, 1898). En 1908, la Escuela Comercial Francesa de México contaba con un campo para la práctica de la gimnasia donde había varios trapecios y barras. Además de la natación, gimnasia, juegos escolares y ejercicios militares, los alumnos podían tomar lecciones de esgrima, boxeo y equitación, previo permiso de sus padres (El Mundo Ilustrado, 1908). En mayo de 1909, la sociedad mutualista "Empleados del Comercio" celebró su xviII aniversario con un festival deportivo a cargo del Club Olímpico. En el festival se realizaron ejercicios en la barra horizontal a cargo de los señores Isunza, Hermenegildo Daz y Heriberto Zárate; los asaltos de boxeo entre este último y don Isaac Zúniga, así como entre Carlos de la Tijera y Joaquín Mendizábal. Además, se realizaron ejercicios en los anillos y luchas grecorromanas (El Mundo Ilustrado, 1909). Cabe resaltar que las agrupaciones mutualistas eran asociaciones voluntarias, de individuos libres e iguales en términos jurídicos y tenían como principios destacados el ser independientes de los poderes públicos y religiosos (Illades, 1996).

A mediados de 1897, se conoce de la existencia de algunos equipos de béisbol en la capital, sobresaliendo entre ellos: el cuc Base Ball Club, el Union Club y el Mexico Base Ball Club (The Mexican Herald, 1897: sp). En 1899, se estableció el Indianilla Base Ball Club (The Mexican Herald, 1899: sp). Además, en la temporada de béisbol de la capital, la inauguraron las novenas del México Base Ball Club y del Circo Orrin (The Mexican Herald, 1899). En este año se fundó el club pelotero Athletics (The Mexican Herald, 1899). Asimismo, llegó a la capital el club beisbolero de Monterrey denominado Monterrey Mexican Cuauhtémoc Base Ball Club, el cual jugó contra el México Base Ball Club. Estas asociaciones peloteras jugaban en un terreno inmediato a la calzada de la Reforma, armando su campamento para jugar todos los domingos (The Mexican Herald, 1899). En 1900, se crearon los clubes Vikings y Ramblers (The Mexican Herald, 1900).

Para 1902, se disputó un partido de béisbol de beneficencia, entre gordos y flacos, con la finalidad de ayudar a los indigentes y desempleados (The Mexican Herald, 1902). En 1904, el Club Juárez jugó un partido contra el Club Águila de Veracruz. Este último se acababa de fundar por obreros de aquel puerto (El Mundo Ilustrado, 1904). Para 1905, el béisbol se jugaba en Chapultepec, Mixcoac, Coyoacán, Guadalupe, San Lázaro, Peralvillo y en distintos puntos de los terrenos situados a uno y otro lado de la calzada de la Reforma, más allá de la glorieta de Cuauhtémoc, pasando a 25 el número de asociaciones organizadas en la capital. Entre los mejores sobresalían: Fronterizo, Estrella - formado en gran parte por cubanos- Berlín, Mixcoac, Juárez, Iris, Boston y Morelos, sin contar 
los formados por alumnos de distintos establecimientos de instrucción como el de la Escuela de Artes y Oficios, el de la Comercial Francesa, Grammar, School, University School y la Escuela de Mascarones (El Mundo Ilustrado, 1905).

Sobre esta expansión capitalina de la práctica del béisbol cabe señalar que los sectores acomodados mexicanos tenían a principios del siglo xx sus casas de campo en Tacubaya, Mixcoac y Coyoacán, que eran pueblos cercanos a la ciudad de México. Además, en 1900, los tranvías de caballos fueron sustituidos por tranvías eléctricos. Esto les posibilitó a las clases alta $y$ media establecerse fuera de la ciudad de México; con el fin de promover entre los sectores trabajadores su asentamiento en barrios hacia el norte y oriente de la ciudad (Buj, 1991).

En 1908, el diamante de béisbol de la Reforma no existía, fue convertido en un centro de recreo de un colegio particular que poco lo usaba, incluso se pensaban dar novilladas en este. Sin embargo, para este último año, se da la existencia de las novenas del Country Club, el Granger, el Tlalpam y el México. Los dos primeros estaban integrados casi totalmente de estadounidenses, con algunos mexicanos, en tanto que los dos últimos estaban formados principalmente de mexicanos (El Mundo Ilustrado, 1908). Esto permite evidenciar la inconstancia en la práctica del deporte en sus inicios en la ciudad de México.

Para 1899, la Sociedad Farmacéutica Mexicana contaba con un salón de boliche ( $L a$ Farmacia, 1899). El 15 de enero de 1907, se conocían los resultados de los juegos de boliche correspondientes a la primera serie del torneo que fueron jugados en el Club Oro, el resumen final da 2248 puntos. Los "Triángulos" vencieron a "Monterrey", "Alvarados" vencieron a "El Oro", el "Oaxaca" venció a "Patoní" y "Aguascalientes" venció a "University Club" (El Imparcial, 1907). El 5 de julio de 1904, en el edificio del Club Cosmopolita se llevó a cabo un torneo de boliche entre los miembros de esta asociación y el Club Oro (La Patria, 1904).

Acerca del fútbol, se tiene que en la tarde del 22 de diciembre de 1901, se realizó un partido entre miembros del Reforma Athletic Club. Los jugadores eran: Forwards:
Blackmore, Crowder, Easton, Watson y Johnston. Half Backs: Cowell, Turner y Paterson. Backs: Rincón Gallardo y Lacaud. Goal: Clifford (The Mexican Herald, 1901). En 1902, se efectuó un partido entre miembros de las colonias inglesa $y$ escocesa (The Mexican Herald, 1902). En 1905, se disputó un partido entre los equipos de la Compañía de Gas y Luz Eléctrica, así como uno conformado por miembros de los clubes Reforma Athletic Club y el Club Británico. Los capitanes fueron Prynce Jones y Madge, respectivamente. El partido estuvo poco interesante, los jugadores estaban faltos de práctica y no hicieron grandes esfuerzos (El Mundo, 1905). La falta de preparación y mala ejecución del balompié por parte de la elite económica se ha podido constatar para el mismo período en Costa Rica y Guatemala (Urbina, 2001 y 2007).

Para 1910, la Escuela Normal contaba con un equipo de fútbol (The Mexican Herald, 1910). En este año la liga de balompié capitalina estaba integrada por los siguientes equipos: Club 1910 de Tacubaya, el de la Escuela Normal, el de la Escuela de Agricultura, el умса (Young Men's Christian Association) y el del Colegio Inglés de Tacubaya (The Mexican Herald, 1910).

Con respecto al golf, se tiene conocimiento que en 1902, el Reforma Athletic Club organizaba dos veces por semana - los jueves y los domingos- partidos de golf. Entre los organizadores se encontraba el capitán Halliwell, Vicecónsul de Inglaterra en México (El Mundo Ilustrado, 1902). Acerca de esta asociación deportiva, cabe mencionar que se fundó en 1894, compuesta principalmente por ingleses y estadounidenses, entre quienes figuraban banqueros, capitalistas, apoderados y representantes de compañías extranjeras (El Mundo Ilustrado, 1904).

Sobre el jiu jitsu, en 1905, el Club Atlético Ugartechea contaba con los señores Larrauri y Moremo como conocedores del este deporte ( $E l$ Mundo Ilustrado, 1905). El miércoles 8 de julio de 1908, se inauguró en el décimo cuarto batallón, en la Piedad, la segunda biblioteca, destinada a la tropa de dicho cuerpo castrense. En los actos que se verificarían para tal fin se encuentra una lucha de jiu jitsu realizada por soldados del batallón (El Imparcial, 1908). El 9 de agosto de 1908, se inauguró la Escuela Japonesa de jiu 
jitsu en la segunda calle del reloj número 10 ( $E l$ Tiempo, 1908). A finales de agosto de 1909, en el Teatro Colon se realizó una lucha de jiu jitsu entre el Conde Koma y un inglés de apellido Black (La Patria, 1909).

En septiembre de este mismo año, el Conde Koma efectuó otra lucha en el Teatro Principal contra Jim Smith (La Patria, 1909). En marzo de 1910, el teniente de artillería Gaspar Ruíz reemplazó al japonés Shinzo Harada como instructor de jiu jitsu en la Escuela de Aspirantes (La Patria, 1910). Para el jueves 28 de abril del año antes citado, la Unión Estudiantil realizó en el Teatro Arbeu un ejercicio de jiu jitsu a cargo de Vicente Nájera y Jacobo Hoheintein $y$ varias luchas de este deporte donde participaron los sargentos Bedoya $y$ Antonio Hernández, y los cabos Ramón Bonilla y Alfonso Ocampo (El Tiempo, 1910). El domingo 22 de mayo de 1910 , se nombró la junta directiva del Club Atlético Internacional compuesto por japoneses. La junta quedó integrada de la siguiente manera: Presidente, Naotaro Kobayashi; vicepresidente, Onkiachi Hayaschi; secretario, Kajiro Aoyama; subsecretario, Kenji Kamagai; tesorero, Rikichi Hara; primer comisario, Tashio Onodera; segundo comisario, Tokularo Himasigu, $y$ doce vocales más (El Tiempo, 1910). El 12 de diciembre de 1910, se inauguró el edificio de la Escuela Normal para Profesores y su Anexa, entre los actos deportivos que se realizaron sobresalen los asaltos de jiu jitsu y de lucha grecorromana (La Iberia, 1910).

Para 1907, el Club Hípico Militar le brindó al General Porfirio Díaz, unas carreras equinas con motivo del aniversario del asalto y toma de Puebla por el Ejército de Oriente el 2 de abril de 1867 (El Mundo Ilustrado, 1907). Para el domingo 14 de enero de 1909, el recién fundado Club Hípico Internacional, integrado por alemanes, organizó una caza de la zorra en los llanos que mediaban entre la ex garita de Bucareli y el rancho de Nápoles, en San Pedro de Los Pinos (El Mundo Ilustrado, 1909). A finales de mayo de 1910, el Club Hípico Militar organizaba una serie de carreras ecuestres a beneficio de la Cruz Roja Mexicana (El Imparcial, 1910).
Con respecto al automovilismo, se conoce que en 1907, el conductor Le Roy en un automóvil marca "Royal" de D. Tirso Sainz, hizo el recorrido del puente de Tacubaya al Panteón de Toluca en 69 minutos y 20 segundos (El Mundo Ilustrado, 1907). El $1^{\circ}$ de marzo de 1907, se inauguró en el Parque Luna, el Club de Patinadores de México formado por jóvenes de los sectores acomodados capitalinos. Al acto de inauguración fueron invitados como padrinos, el Presidente Porfirio Díaz y su esposa doña Carmen Romero Rubio de Díaz (El Mundo Ilustrado, 1907). Para abril de 1908, en la $4^{\text {a }}$ de Nuevo México 96, funcionaba una Academia de baile $y$ de patines (El Imparcial, 1908). En la noche del martes 21 de diciembre de 1909 se efectuó en el Parque Luna una sesión de patines organizada por el Club Violeta (El Imparcial, 1909).

Sobre el polo, en 1908 funcionaba el Polo Club, el cual estaba integrado por don Felipe Iturbe, don Ignacio de la Torre y Mier (Conde de Soubervielle), don Ignacio Algara, don Patricio Sanz, don Alejandro de la Arena y don Francisco Suinaga (El Mundo Ilustrado, 1908).

Acerca del papel en la propagación de la práctica del deporte y la celebración de la independencia, en 1906, el Club Olímpico era el mayor centro de educación física de la capital, por lo que el Ministerio de Instrucción Pública decidió patrocinarlo, subvencionándolo y enviándole a los estudiantes de las escuelas profesionales. Por su parte, el Reforma Athletic Club -el más importante centro deportivo de las colonias extranjeras- poseía un campo deportivo en la zona de la Reforma. Esta asociación había creado el "Día de Sport" que celebraba cada 12 de diciembre y era una de las más atrayentes actividades organizadas de la capital. Poseía el campeonato de balompié y el record de las carreras de relevos. El México Country Club era el mejor instalado de todo el país, se encontraba en Churubusco. Entre los deportes que ejecutaba estaban el golf, el criquet, el tenis y el beisbol (El Mundo Ilustrado, 1907).

El domingo 20 de setiembre de 1908, el Club Hércules realizó en la Villa de Guadalupe Hidalgo, la última fiesta deportiva con la que conmemoró el aniversario de la independencia nacional. Frente a la entrada de los antiguos 
baños de Aragón, se colocó la tribuna para las reinas de las fiestas y para el público, como pista se uso la calzada que conduce de esta villa a la ciudad capital. Los actos deportivos comenzaron con una carrera de bicicleta de 300 metros de distancia que fue ganada por un señor de apellido Riquelme quien recibió como premio una medalla de plata; igual premio se le concedió al señor García Heras, vencedor de la carrera ciclista de 500 metros. Al vencedor de la tercera carrera de 1000 metros de distancia se le regaló un estuche de viaje. Don Guadalupe Moreno ganó la carrera de resistencia de 4873 metros que consistió en el ascenso y descenso del cerro Gachupines, quien recibió como premio un reloj de oro. Después se hicieron tres carreras ecuestres de 300 y 400 metros que fueron ganadas por el teniente Benjamín González, el teniente Antonio Escoto y el teniente Manuel Saavedra (El Mundo Ilustrado, 1908). La práctica de dedicar partidos a señoritas o damas destacadas fue también muy común en Centroamérica (Urbina, 2001 y 2007).

\section{CONCLUSIÓN}

La prensa capitalina transmitió un discurso higienista-moralizador sobre el cuidado del cuerpo y la influencia regeneradora de la práctica del deporte; sin embargo, esta disertación no fue la única debido a que también existió una posición conservadora apegada al tradicionalismo frente al avance de la práctica del deporte. Esto demuestra el interés de la prensa en apoyar la política del Estado mexicano en instruir, moralizar $y$ transmitir un sentimiento de identidad nacional a la población infantil urbana acomodada, principalmente.

El nacimiento del deporte moderno en México DF nace en seno de la burguesía capitalina mexicana $y$ de las principales colonias extranjeras radicadas en esa urbe como la inglesa, la estadounidense, la española, la alemana, la francesa y la japonesa. En el período de 1851 a 1910, surgen disciplinas deportivas como las carreras de caballos, esgrima, gimnasia, natación, boliche, regatas, pelota vasca, ajedrez, ciclismo, boxeo, lucha grecorromana, atletismo, beisbol, patinaje, fútbol, golf, jiu jitsu, criquet y tenis.
Cabe destacar que en sus inicios en el país, el deporte moderno estuvo dominado por disciplinas individuales, hecho que hizo que los sectores que comenzaron a ejercitarse en ellos, consideraran su práctica como un acto social, por lo que la adecuada preparación y entrenamiento estuvieron en una gran medida ausentes.

Es con el nacimiento del béisbol en 1897, que los sectores trabajadores urbanos entraron a la arena deportiva, por lo que se puede considerar que este deporte contribuyó en la formación de un sentido de clase entre esos grupos sociales. Empero, la mala organización y la pobreza de sus organizaciones, el poco apoyo de los líderes comunales, tanto seculares como religiosos, así como la no existencia de campos adecuados para las prácticas, hicieron que sus asociaciones deportivas tuvieran en general una vida efímera.

\section{BIBLIOGRAFÍA}

LIBROS

Ariès, Philippe y Duby, Georges (Directores). "De la révolution à la grande guerre". Historie de la vie privée. Volume dirigé par Michelle Perrot. Paris, Francia: èditions du Senil, 1999.

Bazant, Mílada. La historia de la educación durante el porfiriato. México: Centro de Estudios Históricos de El Colegio de México, 1993.

Beezley, William H. Judas at the Jockey Club and other episodes of Porfirian Mexico. University of Nebraska, 2004.

Botey, Carlota; Semo, Enrique; García de León, Antonio y Escárcega, Everardo. Historia de la cuestión agraria mexicana. El siglo de la hacienda 18001900. México DF, México: Siglo xxi, 1988.

Bourdieu, Pierre. La distinción. Taurus: Madrid, 1988.

Clark de Lara, Belem y Speckman Guerra, Elisa (coordinadores). La República de las Letras: asomos a la cultura escrita del México decimonónico. México: Instituto de Investigaciones Filológicas de la Universidad Nacional de México (UNAMIIFL), 2005. 
Cosío Villegas, Daniel. Historia moderna de México (10 volúmenes). México: Editorial Hermes, 1955-1972.

Elías, Norbert y Dunning, Eric. Deporte y ocio en el proceso de la civilización. Madrid, España: Fondo de Cultura Económica, 1996.

García Canclini, Néstor. Consumidores y ciudadanos. Conflictos multiculturales de la globalización. México DF: Editorial Grijalbo, 1995.

Garner, Paul. Porfirio Díaz del héroe al dictador. México: Planeta, 2003.

Garza, Gustavo (compilador). Una década de planeación urbano-regional en México, 1978-1988. 1a. reimpr. México: El Colegio de México, 1992.

Gilbert M., Joseph. Revolution from without: Yucatán, México, and the United States, 1880-1924. Reino Unido: Cambridge University Press, 1982.

Glantz, Margo (coord.). Del fistol a la linterna. Homenaje a José Tomás de Cuéllar y Manuel Payno en el centenario de su muerte. México: Coordinación de Humanidades de la Universidad Autónoma de México (UNAM), 1997.

Guerra, François Xavier. México, del antiguo régimen a la revolución 2. México: Fondo de Cultura económica (FCE), 1988.

Illades, Carlos. Hacia la república del trabajo. La organización artesanal de la ciudad de México 1853-1876. México: El Colegio de México y Universidad Autónoma Metropolitana Iztapalapa, 1996.

Lida, Clara E. y Pérez Toledo, Sonia (comps.), Trabajo, ocio y coacción. Trabajadores urbanos en México y Guatemala en el siglo XIX. México: Universidad Autónoma de México UAM-Iztapalapa/Miguel Ángel Porrúa, 2001.

Roeder, Ralph. Juárez y su México. México DF, México: Secretaría de Educación Pública, 1952.

Urbina Gaitán, Chester. Costa Rica y el deporte (1873-1921). Un estudio acerca del origen del fútbol y la construcción de un deporte nacional. Heredia, Costa Rica: Editorial de la Universidad Nacional, 2001.
Urbina Gaitán, Chester. Deporte y Nación (1881-1950). El caso del fútbol en Guatemala. Guatemala: Facultad Latinoamericana de Ciencias Sociales (FLACSO), 2007.

Vásquez K., Josefina. Nacionalismo y educación en México. México DF: El Colegio de México, 2000.

Viqueira, Juan Pedro. ¿Relajados o reprimidos? Diversiones públicas $y$ vida social en la ciudad de México durante el siglo de las Luces. México DF, México: FCE, 1987.

Ward, Peter M. México: una megaciudad. Producción y reproducción de un medio ambiente urbano. Lili de Buj (Trad.). México: Consejo Nacional para la Cultura y las Artes, Alianza Editorial, 1991.

\section{PUBLICACIONES PERIÓDICAS}

Angelotti Pasteur, Gabriel. "Deporte y nacionalismo en México durante la post revolución". Record. Revista de História do Esporte 1 (4). Junio, 2011. [En línea]. En: <http://www.sport.ifcs.ufrj.br/ recorde/pdf/recordeV4N1_2011_12.pdf> [Consultado el 12 de octubre de 2011]

Aréchiga Córdoba, Ernesto. "Educación, propaganda o "dictadura sanitaria". Estrategias discursivas de higiene y salubridad públicas en el México posrevolucionario, 1917-1945". México: UNAN. Estudios de Historia Moderna y Contemporánea de México 33. EneroJunio 2007.

Hale, Charles A., "Los mitos políticos de la nación mexicana: el liberalismo y la Revolución". Historia Mexicana 4 (xlvi). México DF: El Colegio de México, 1997.

Instituto de Investigaciones Bibliográficas. Boletín 1-2 (10). México: Universidad Nacional de México (UNAM), 2005.

Instituto de Investigaciones Bibliográficas. Boletín 1-2 (13). México: Universidad Nacional de México (UNAM), 2008.

Falco Genovez, Patricia. "El desafío de Clío: el deporte como objeto de estudio de la historia”. efdeportes 9 (3). Buenos Aires, Argentina. Marzo, 1998. [En línea]. En: 
$<$ http://www.efdeportes.com/efd9/cliole. htmDocument2>

López Sánchez, Oliva. "Cuerpo y salud en los ciudadanos del Distrito Federal en la segunda mitad del siglo XIX". Revista Electrónica de Psicología Iztacala 2(12). Junio, 2009. [En línea]. En: <http:// renisce.files.wordpress.com/2012/04/artrev-psicologc3ada_vol12no2art1.pdf> [Consultado el 12 de octubre de 2011]

Rodríguez Hernández, Georgina. "Orden, progreso y sport”. Luna córnea. 16. México DF: Conaculta. Septiembrediciembre, 1998.

Pérez-Rayón, Elizundia Nora. "México 1900: la modernidad en el cambio de siglo. La mitificación de la ciencia". Estudios de Historia Moderna y Contemporánea de México 18. México: Instituto de Investigaciones Históricas de la Universidad Nacional de México (UNAM). 1998. [En línea]. En: <http:// www.historicas.unam.mx/moderna/ ehmc/ehmc18/233.htmlDocument2> [Consultado el 12 de octubre de 2011].

Urbina Gaitán, Chester. "Origen del Deporte en El Salvador (1885-1943)”. Realidad y reflexión. 17. 6. San Salvador: Universidad Francisco Gavidia. Mayoagosto, 2006.

Toledo, Carlos Oliver. "Higiene mental y prácticas corporales en El Porfiriato". Revista Electrónica de Psicología Iztacala 2 (12). Universidad Nacional de México (unam), junio, 2009. En: <http://www.iztacala.unam.mx/ carreras/psicologia/psiclin/vol12num2/ Vol12No2Art2.pdf> [Consultado el 13 de octubre de 2011].

Urbina Gaitán, Chester. "El espectáculo salvaje. Los inicios del boxeo en Costa Rica (1906-1929)". EFDeportes 159. Buenos Aires, Argentina. Agosto, 2011. En: $<$ http://www.efdeportes.com/efd159/losinicios-del-boxeo-en-costa-rica.htm> [Consultado el 14 de octubre de 2011].

Urbina Gaitán, Chester. "Fútbol e identidad nacional en Centroamérica. Un análisis comparativo de los casos de Guatemala,
El Salvador y Costa Rica”. Revista de Ciencias Sociales 113-114. San José: Universidad de Costa Rica. 2006a: 177187. [En línea]. En: <http://www.latindex. ucr.ac.cr/rcs-113-114/14-URBINA.pdf $\geq$ [Consultado el 14 de octubre de 2011].

Urbina Gaitán, Chester. "La revista costarricense Cordelia y el ejercicio físico en la mujer". EFDeportes 149. Buenos Aires, Argentina. Octubre, 2010. [En línea]. En: <http://www.efdeportes.com/ efd149/la-revista-cordelia-y-el-ejerciciofisico-en-la-mujer.htm> [Consultado el 14 de octubre de 2011].

Urbina Gaitán, Chester. "Orígenes del deporte moderno en El Salvador (1895-1921)". EFDeportes 97. Buenos Aires, Argentina. Junio, 2006b. [En línea]. En: <http:// www.efdeportes.com/efd97/salvador.htm> [Consultado el 15 de octubre de 2011].

Zamora Perusquía, Gerson Alfredo. "El deporte en la ciudad de México (1896-1911)". Históricas 91. Boletín del Instituto de Investigaciones Históricas. México: Universidad Nacional de México (UNAM). Mayo-Agosto, 2011. [En línea]. En: <http://www.historicas.unam.mx/ publicaciones/revistas/boletin/pdf/ bol91/bol9101.pdf> [Consultado el 15 de octubre de 2011].

\section{HEMEROTECA NACIONAL DE MÉXICO}

Archivo Mexicano. Febrero 16 de 1853. Tomo I. No.8.

Diario del Hogar. Domingo 14 de julio de 1895. Tomo XIV. No.255.

Diario del Hogar. Viernes 31 de enero de 1896. Año Xv. No.117.

El Abogado Cristiano. Marzo 12 de 1908.

El Demócrata. Miércoles 20 de noviembre de 1895. Tomo III. No.333.

El Demócrata. Sábado 18 de enero de 1896. Tomo IV. No.380.

El Derecho. Sábado 28 de mayo de 1870 . Tomo IV. No. 22.

El Diario del Hogar. Domingo 23 de abril de 1883. Tomo I. No. 171.

El Faro Homeopático. Tomo I. México. Imp. y Lit. de J. Rivera Hijo y Comp. Calle 
del coliseo viejo, bajos de la Gran Sociedad, 1874.

El Ferrocarril. Jueves 3 de noviembre de 1870. Tomo III. No. 255.

El Ferrocarril. Martes 9 de mayo de 1871. Tomo IV. No.107.

El Imparcial. Miércoles 16 de enero de 1907. Tomo xxI. No.3760.

El Imparcial. Martes 7 de julio de 1908. Tomo xxv. No. 4298.

El Imparcial. Miércoles 4 de noviembre de 1908. Tomo xxv. No.4430.

El Imparcial. Viernes 27 de agosto de 1909. Tomo xxviI. No.4726.

El Imparcial. Jueves 23 de diciembre de 1909. Tomo xxviI. No. 4344.

El Imparcial. Domingo 22 de mayo de 1910. Tomo XXVII. No.4994.

El Imparcial. Domingo 7 de agosto de 1910. Año Xxix. No.5071.

El Imparcial. Martes 20 de septiembre de 1910. Año xxix. No. 6015.

El Monitor Republicano. Sábado 17 de mayo de 1851. Año VII. No.2187.

El Monitor Republicano. Domingo 19 de enero de 1868. Año XviII. No.4850.

El Monitor Republicano. Jueves 30 de mayo de 1872. Año XXII. No.129.

El Monitor Republicano. Miércoles 5 de junio de 1872. Año XXII. No. 134.

El Monitor Republicano. Viernes 21 de abril de 1882. Año Xxxir. No. 95.

El Monitor Republicano. Sábado 21 de diciembre de 1895. Año XLV. No. 305.

El Mosaico. Agosto 26 de 1894. Año II. No.32.

El Mundo Ilustrado. Noviembre 18 de 1900. Año VII. No. 21.

El Mundo Ilustrado. Junio 15 de 1902. Año IX. No. 24.

El Mundo Ilustrado. Junio 29 de 1902. Año IX. No.26.

El Mundo Ilustrado. Abril 24 de 1904. Año XI. No.17.

El Mundo Ilustrado. Marzo 20 de 1904. Año X. No. 12.

El Mundo Ilustrado. 9 de julio de 1905.

El Mundo Ilustrado. 10 de marzo de 1907. Año XIV. No.10.

El Mundo Ilustrado. 14 de abril de 1907. Año XIV. No. 15.
El Mundo Ilustrado. 1 de marzo de 1908.

El Mundo Ilustrado. 8 de marzo de 1908. Año Xv. No.10.

El Mundo Ilustrado. 15 de noviembre de 1908. Año Xv. No. 20.

El Mundo Ilustrado. 23 de mayo de 1909. Año XVI. No. 21.

El Mundo Ilustrado. 25 de abril de 1909. Año XVI. No. p.956.

El Mundo Ilustrado. 27 de septiembre de 1908. Año Xv. No. 13.

El Mundo Ilustrado. 31 de enero de 1909. Año XVI. No. 5.

El Mundo. Miércoles 9 de agosto de 1905. Tomo XIX. No. 2555.

El Mundo. Agosto 13 de 1905. Año XII. No.7.

El Mundo. 1 de enero de 1907.

El Municipio Libre. Martes 10 de septiembre de 1889. Tomo Xv. No.212.

El Nacional. Lunes 5 de mayo de 1896. Año xxviII. No.254.

El Partido Liberal. Viernes 30 de agosto de 1895. Tomo xx. No.3074.

El Siglo Diez y Nueve. Miércoles 10 de agosto de 1892. Año 51. No.16385.

El Siglo Diez y Nueve. Viernes 9 de octubre de 1896. Tomo $11^{\circ}$. No. 17.633 .

El Siglo Diez y Nueve. Miércoles 14 de octubre de 1896. Tomo 11. No.17.637.

El Tiempo. Martes 23 de junio de 1903.

El Tiempo. Domingo 9 de agosto de 1908. Año Xxvi. No. 8337.

El Tiempo. Viernes 12 de febrero de 1909. Año III. No. 823.

El Tiempo. Lunes 25 de abril de 1910. Año XXvII. No.8842.

El Tiempo. Lunes 23 de mayo de 1910. Año XXVII. No. 8865.

El Universal. Sábado 15 de julio de 1899. Tomo XVII. No.162.

El Universal. Miércoles 22 de agosto de 1900. Tomo I. No.243.

La Farmacia. Abril 15 de 1899. Tomo viII. No.4.

La Iberia. Jueves 3 de diciembre de 1868. Tomo IV. No. 511.

La Iberia. Jueves 31 de octubre de 1907. Año II. No.446.

La Iberia. Viernes 12 de febrero de 1909. Año III. No.825. 
La Iberia. Miércoles 14 de diciembre de 1910. Año V. No. 1864.

La Patria de México. Domingo 3 de enero de 1897. Año XXI. No.6058.

La Patria. Jueves 7 de julio de 1904. Año XxviII. No. 8273.

La Patria. Sábado 28 de agosto de 1909. Año xxxiII. No. 9455.

La Patria. Jueves 2 de septiembre de 1909. Año xxxiII. No. 9459 .

La Patria. Lunes 7 de marzo de 1910. Año Xxxix. No. 9610.

La Semana de las Señoritas Mejicanas. Tomo III. México: Imprenta de Navarro, 1852.

La Voz de México. Sábado 6 de junio de 1896. Tomo xxviI. No.126.

Legislación Mexicana o Colección Completa de las disposiciones legislativas expendidas desde la independencia de la República. Ordenada por los Licenciados Manuel Dublan y José María Lozano. Edición Oficial. Tomo vi. México: Imprenta del Comercio, de Dublan y Chaves, 1877.

Legislación Mexicana o Colección Completa de las disposiciones legislativas expendidas desde la independencia de la República. Ordenada por los Licenciados Manuel Dublan y José María Lozano. Edición Oficial. Tomo vi. México: Imprenta del Comercio, de Dublan y Chaves, 1878.

Legislación Mexicana o Colección Completa de las disposiciones legislativas expendidas desde la independencia de la República. Ordenada por los Licenciados Manuel Dublan y José María Lozano. Edición Oficial. Tomo XIV. México: Imprenta y Litografía de Eduardo Dublan y Comp. Coliseo Viejo, Bajos de la Gran Sociedad, 1886.

Legislación Mexicana o Colección Completa de las disposiciones legislativas expendidas desde la independencia de la República. Ordenada por los Licenciados Manuel Dublan y José María Lozano. Edición Oficial. Tomo xxviI. México: Imprenta de Eduardo Dublan, Callejón de Cincuenta y Siete No. 7, 1898.

The Two Republics. Saturday, December 2, 1871. Vol. 5. No.23.
The Two Republics. Tuesday, October 7, 1890. Vol. 31. No. 72

The Mexican Herald. Monday, December 23, 1895. Vol. I. No.114.

The Mexican Herald. Wesneday, June 30, 1897. Vol. III. No. 126.

The Mexican Herald. Saturday, March 11, 1899. Vol. viI. No.189.

The Mexican Herald. Tuesday, March 28, 1899. Vol. viI. No.206.

The Mexican Herald. Monday, April 10, 1899. Vol. vII. No.217.

The Mexican Herald. Friday, May 5, 1899. Vol. VII. No.242.

The Mexican Herald. Monday, January 22, 1900. Vol. Ix. No. 145.

The Mexican Herald. Sunday, December 22, 1901. Vol. XIII. No.114.

The Mexican Herald. Saturday, February 8, 1902. Vol. XIII. No.159.

The Mexican Herald. Wesneday, December 16, 1902. Vol. xv. No.101.

The Mexican Herald. Tuesday, March 15, 1910. Vol. xxix. No. 196.

The Mexican Herald. Saturday, April 16, 1910. Vol.xxx. No.16.

TEXTOS ELECTRÓNICOS

Pérez González, Carmen. "El deporte en el ámbito de la Unión Europea”. El modelo europeo del deporte. 2002. [En línea]. En: <http://www. facedoabogados.com/articulos/ d e porteue.htm Document $2>$ [Consultado el 13 de octubre de 2011]

Mendoza Ruíz, Martín. El deporte en México en la época contemporánea. Instituto Veracruzano de Educación Superior. 19 de enero de 2012. [En línea]. En: <http://martinmendozaruiz. blogspot.com/2012/01/el-deporte-enmexico-desde-1900.htmlDocument2> [Consultado el 13 de octubre de 2011]

TESIS

Angelotti, Pasteur, Gabriel H. "La dinámica del fútbol en México. La construcción de identidades colectivas en torno al Club 
de Fútbol Pachuca en nuestros días". [Tesis en Antropología Social]. El Colegio de Michoacán, 2004.

Chávez González, Mónica. "La introducción de la educación física en México: Representaciones sobre el cuerpo y el género, 1882-1928". [Tesis de Maestría en Historia]. El Colegio de San Luis, 2004.
Torres Sánchez, Rafael. "Revolución y vida cotidiana. Guadalajara, 1914-1934". [Tesis de doctorado]. México, Universidad Nacional Autónoma de México: 1996.

Fecha de ingreso: 24/ 09/2012 Fecha de aprobación: 29/04/2013 
